\title{
Machine Vaping of Electronic Cigarettes - A Comparison of Puffing Regimes ${ }^{\#, *}$
}

\author{
by \\ Amit Gupta ${ }^{1}$, Rana Tayyarah ${ }^{2}$, Gene Gillman $^{3}$, Charles Garner ${ }^{4}$, and Rob Stevens ${ }^{4}$ \\ Battelle Memorial Institute, 505 King Avenue, Columbus OH, USA \\ ITG Brands, LLC, PO BOX 21688, Greensboro NC, USA \\ Enthalpy Analytical LLC., 800 Capitola Dr., Durham NC, USA \\ 4 RAI Services Company, 401 North Main Street, Winston Salem NC, USA
}

\section{SUMMARY}

Several machine-based puffing regimes for collection of e-cigarette aerosol were evaluated with the objective of recommending one regime for standardization. The study involved a comparison of several candidate regimes for which puff volume, duration, interval, profile shape, and puff number were defined and varied. Testing was conducted at four laboratories using seven e-cigarette test products. Each participating laboratory generated and analyzed aerosol from the test products for glycerin, propylene glycol, water, and nicotine using the candidate regimes. Results were compared within each product's data set to understand the impact of the regimes on product yield, consistency of results, and reliability of the testing equipment. Each of the regimes evaluated was determined to be fit for purpose for the range of products tested. Based on specific selection criteria, the recommended collection parameters are a square-shaped 55-mL puff of $3 \mathrm{~s}$ duration with a puff frequency of one puff every $30 \mathrm{~s}$. Standardized reporting parameters include aerosol collected mass (ACM), puff count, and e-cigarette weight loss along with analyte yield on a per-puff basis and total-puffs basis. [Contrib. Tob. Nicotine Res. 30 (2021) 127-136]

\# This manuscript is an output of work carried out in CORESTA E-Vapour (EVAP) Sub-Group

* Received: $16^{\text {th }}$ November 2020 - accepted: $24^{\text {th }}$ March 2021

\section{ZUSAMMENFASSUNG}

Es wurden mehrere maschinelle Zugprotokolle zur Erfassung von E-Zigarettenaerosol mit dem Ziel ausgewertet, eines der Protokolle zur Standardisierung zu empfehlen. Im Rahmen der Untersuchung erfolgte ein Vergleich verschiedener potenziell geeigneter Protokolle, bei denen Volumen, Dauer, Intervall, Profilform und Anzahl der Züge definiert und variiert wurden. Die Untersuchungen wurden in vier Laboren an sieben E-Zigaretten-Testprodukten durchgeführt. Jedes teilnehmende Labor erzeugte mit den Testprodukten Aerosol und analysierte für die verschiedenen Protokollkandidaten den Gehalt an Glyzerin, Propylenglykol, Wasser und Nikotin. Die Ergebnisse wurden jeweils innerhalb der produktspezifischen Datensätze verglichen, um den Einfluss der Protokolle auf die Produktausbeute, die Konsistenz der Ergebnisse sowie die Zuverlässigkeit der Prüf- und Messgeräte zu verstehen. Für jedes der bewerteten Protokolle wurde festgestellt, dass es für die untersuchte Produktpalette geeignet ist. Auf der Grundlage spezifischer Auswahlkriterien werden folgende Erfassungsparameter empfohlen: ein Zug von $55 \mathrm{~mL}$ mit quadratischem Zugprofil und einer Dauer von 3 s sowie einer Zugfrequenz von einem Zug alle $30 \mathrm{~s}$. Zu den standardisierten Berichtsparametern zählen die erfasste Aerosolmasse (ACM), die Anzahl der Züge und der Gewichtsverlust der E-Zigarette sowie die Analytenausbeute pro Zug und pro Gesamtzahl der Züge. [Contrib. Tob. Nicotine Res. 30 (2021) 127-136] 


\section{RESUME}

Dans le but de recommander un régime à des fins de normalisation, plusieurs paramètres de fumage machine visant la collecte des aérosols émis par les cigarettes électroniques furent évalués. La présente étude repose sur un comparatif de plusieurs régimes candidats pour lesquels le volume, la durée, l'intervalle, la forme du profil de bouffée et le nombre de bouffées firent l'objet d'une définition et de variations. Les essais furent menés dans quatre laboratoires fumant sept produits de cigarettes électroniques. Chaque laboratoire participant généra et analysa les aérosols émis par les produits d'expérimentation afin de déterminer la teneur en glycérine, propylène glycol, eau et nicotine pour chacun des régimes candidats. Les résultats furent comparés à l'intérieur du jeu de données de chaque produit afin de comprendre l'incidence des régimes sur le rendement des produits, sur la cohérence des résultats et sur la fiabilité de l'équipement d'expérimentation. Chacun des régimes évalués fut qualifié d'apte à l'emploi pour la gamme de produits testés. Sur la base de critères de sélection spécifiques, les paramètres de collecte recommandés sont une bouffée de $55 \mathrm{~mL}$, avec un profil de bouffée carré et d'une durée de 3 secondes pour une fréquence de bouffée d'un tirage toutes les 30 secondes. Les rapports normalisés incluent les paramètres tels que la masse d'aérosol collectée (MCA), le décompte des bouffées et la perte de poids de la cigarette électronique ainsi que le rendement des analytes calculé par bouffée individuelle et pour la totalité des bouffées. [Contrib. Tob. Nicotine Res. 30 (2021) 127-136]

\section{ABBREVIATIONS}

$\begin{array}{ll}\text { ACM } & \begin{array}{l}\text { Aerosol collected mass } \\ \text { CI }\end{array} \\ \text { CORESTA } & \begin{array}{l}\text { Cooperation Centre for Scientific Research } \\ \text { Relative to Tobacco } \\ \text { Gas Chromatograph - Flame Ionization } \\ \text { Detector } \\ \text { Gas chromatography-thermo conductivity } \\ \text { detector }\end{array} \\ \text { GC-TCD } & \begin{array}{l}\text { International Organization for Stan- } \\ \text { dardization }\end{array} \\ \text { ISO } & \begin{array}{l}\text { Flame ionization detector } \\ \text { Propylene glycol }\end{array} \\ \text { FID } & \text { PG }\end{array}$

\section{INTRODUCTION}

Electronic nicotine delivery systems (ENDS) are e-cigarette products that deliver flavor and nicotine to the consumer from a nicotine-containing liquid matrix that is thermally aerosolized by a resistive heating element. Most e-cigarettes consist of an atomizer, a power source such as a battery, and a container of e-liquid such as a cartridge or a tank. Upon activation of puff, the battery-powered atomizer vaporizes the e-liquid which then condenses to form the aerosol. Depending upon the puffing parameters used, such as puff duration, puff volume, etc., amounts of aerosol generated per puff may vary significantly.
At the time this study was conducted in 2015 , relatively little published analytical data existed for commercial e-cigarette products and no standardized aerosol collection puffing regime existed. A literature review conducted at the time of this study found researchers were collecting samples with puff volumes ranging from $35 \mathrm{~mL}-70 \mathrm{~mL}$, puff durations ranging from $<2 \mathrm{~s}$ to $5 \mathrm{~s}$ and puff frequencies of one puff every $10 \mathrm{~s}$ to $60 \mathrm{~s}$ (1). Some researchers used non-standard puffing devices which had been developed in their own laboratories. These generally included a simple apparatus involving syringes or vacuum pumps that are unlikely to be suitable for standardization of collection methodologies (2). Thus, analytical characterization results reported in the literature could not be adequately compared due to differences in study designs and aerosol collection parameters and apparatus. Standardization is critical to allow researchers to use and build on each other's work and for regulatory bodies to develop a basis under which to develop product requirements.

To standardize the collection of e-cigarette aerosol, the CORESTA E-Vapor Sub-Group conducted a study to understand the impact of puff volumes from $35 \mathrm{~mL}-70 \mathrm{~mL}$, puff durations from $<2 \mathrm{~s}$ to $5 \mathrm{~s}$ and puff frequencies of one puff every $30 \mathrm{~s}$ and $60 \mathrm{~s}$ on the generation of aerosol (3). In this study, the mechanism to generate the aerosol included automated conventional cigarette smoking machines (4). The study involved a comparison of potential candidate puffing regimes in which puff volume, duration, frequency, profile shape, puff number, and puff profile was defined for each test candidate regime. Each participating laboratory tested e-cigarette products of their choice for each of the analytes - glycerin, propylene glycol (PG), water, and nicotine - using the specified regimes. Results were compared within each product's data set to understand the impact of the regimes on yield, consistency of results, and reliability of the testing equipment. Recommendations for a standard regime and standardized reporting information are provided.

Based on the recommendations from this study, the CORESTA E-Vapor Sub-Group later developed CORESTA Recommended Methods (CRMs) for routine analytical testing for e-cigarette aerosol generation and collection (7) and testing of major components in e-cigarette aerosol (6).

\section{MATERIALS AND METHODS}

\section{$2.1 \quad$ Test products}

Four laboratories participated in this study (Labs 1 through 4). Each study participant was asked to test one disposable e-cigarette product and one rechargeable e-cigarette product of choice. The identities of the products were not disclosed. Information for each of the products is listed in Table 1. The results of product characterization given in Table 7 show that different products were used across the laboratories. As a disposable product of their choice, Lab 1 used a 3-piece e-cigarette product (e.g., battery, vaporizing chamber and cartomizer). The laboratory reported an experimental issue while testing this product, making the data obtained using this product potentially unreliable. The raw data obtained using this sample was not considered with regards to overall conclusions drawn from this study. 
Table 1. Product information. List of e-cigarette products tested.

\begin{tabular}{ll}
\hline Sample ID & Sample Description $^{\text {a }}$ \\
\hline Lab 1-Rechargeable & Rechargeable product tested by Laboratory 1 \\
Lab 2-Rechargeable & Rechargeable product tested by Laboratory 2 \\
Lab 2-Disposable & Disposable product tested by Laboratory 2 \\
Lab 3-Rechargeable & Rechargeable product tested by Laboratory 3 \\
Lab 3-Disposable & Disposable product tested by Laboratory 3 \\
Lab 4-Rechargeable & Rechargeable product tested by Laboratory 4 \\
Lab 4-Disposable & Disposable product tested by Laboratory 4
\end{tabular}

a Each of four labs selected a product of their choice

All samples were stored at room temperature in original packaging prior to analysis. Laboratories were instructed to ensure that rechargeable products' batteries were fully charged according to product instruction prior to analysis.

\subsection{Aerosol collection}

Aerosol was collected via machine-puffing from individual e-cigarette units using a segmented collection approach. Aerosol samples in puff blocks of 25 puffs per puff block were collected until battery depletion, as indicated by product LEDs, etc. or until 300 total puffs were collected. Between each block of 25 puffs, the e-cigarettes were weighed to note weight loss. Five replicates were tested for each measurement. All laboratories used Cerulean SM450 20-port linear smoking machines and 44-mm glass fiber filter pads with $>99 \%$ particulate trapping efficiency which had been conditioned in an atmosphere of $60 \%$ relative humidity and $22^{\circ} \mathrm{C}$. Additionally, room conditions during collection were not specified but all laboratories tested under target conditions of $60 \%$ relative humidity and $22{ }^{\circ} \mathrm{C}$. The filter pads were weighed before and after collection to note aerosol collected mass (ACM). Puff counts were recorded. Specified collection regimes are shown in Table 2.

\subsection{Analytical assays}

The study plan includes the determination of ACM, PG, nicotine, water, glycerin, and product weight loss. The $\mathrm{ACM}$, which is the measure of total aerosol collected, and the weight loss of the e-cigarette were determined gravimetrically. Alternatively, for the latter, device weight loss could have been used for the same purpose. Analytes were determined using the method of choice by each laboratory. The laboratories' methods were similar and may be described as a single general method. For all laboratories, glass fiber filter pads were extracted using organic solvent $(10 \mathrm{~mL}-20 \mathrm{~mL})$, which was typically an alcohol such as isopropanol with agitation ( $20 \mathrm{~min}-30 \mathrm{~min})$. Extracts were further diluted as needed to fall within the calibration range of each method. Water was determined by GC-TCD typically using a capillary column such as Agilent DBWAX (Santa Clara, CA, USA), or a packed column, such as Supelco Porapak R (Saint Louis, MO, USA). Other analytes were quantified by GC-FID using a capillary column, typically DB-WAX (Agilent), or equivalent. Calibration was typically linear with $6-12$ standards with a coefficient of determination $\left(\mathrm{R}^{2}\right)$ of $>0.99$. The results obtained from these analyses were tabulated as mean \pm one standard deviation for levels of selected compounds.

\subsection{Exclusion of outliers}

Traditional outlier tests were not applied in this study since samples and methods were not in common among the testing laboratories. Data for devices that clearly did not function were removed by visual observation. When collecting puff-by-puff (or puff blocks, in this case), puffs near the end of the devices' lifetime (end-of-life), as indicated by significant decrease in ACM yields or from a physical signal (such as a blinking LED) from the product, are typically of high variability. End-of-life puff block yields were included in total yield calculations, but the variability information was not included in the overall assessment of the product's variability under a given regime.

In general, if a product or device had a lower than typical yield for a puff block the next puff block would have a higher than typical yield. Therefore, even though there may have been puff block to puff block variability for a device, the cumulative yields were consistent with the other replicates. Also, analytes tended to correlate with total $\mathrm{ACM}$; if the ACM was low for a measurement, all other analytes were low by a similar magnitude. Thus, data were normalized to ACM in order to account for any values that did not track with ACM for outlier investigation.

Table 2. Regimes specifications. Puffing parameters for aerosol collection.

\begin{tabular}{|c|c|c|c|c|c|c|}
\hline Regime & Code & $\begin{array}{c}\text { Puff volume } \\
(\mathrm{mL})\end{array}$ & $\begin{array}{c}\text { Duration } \\
(\mathrm{s})\end{array}$ & Shape & Frequency & $\begin{array}{c}\text { Mean flow } \\
(\mathrm{mL} / \mathrm{s})\end{array}$ \\
\hline Regime 1 & $55 / 3 / 30 / \mathrm{Sq}$ & 55 & 3 & Square & Every $30 \mathrm{~s}$ & 18.3 \\
\hline Regime 2 & $55 / 4 / 30 / \mathrm{Sq}$ & 55 & 4 & Square & Every $30 \mathrm{~s}$ & 13.8 \\
\hline Regime 3 & $70 / 3 / 30 / \mathrm{Sq}$ & 70 & 3 & Square & Every $30 \mathrm{~s}$ & 23.3 \\
\hline Regime 4 & $70 / 4 / 30 / \mathrm{Sq}$ & 70 & 4 & Square & Every $30 \mathrm{~s}$ & 17.5 \\
\hline ISO-like ${ }^{a}$ & 35 / 2 / 60 / B & 35 & 2 & Bell & Every $60 \mathrm{~s}$ & 17.5 \\
\hline Cl-like ${ }^{a}$ & $55 / 2 / 30 / B$ & 55 & 2 & Bell & Every $30 \mathrm{~s}$ & 27.5 \\
\hline
\end{tabular}

a These regimes were not under evaluation because of previously reported issues with some products but were included for informational purposes because they are based on standardized methods (ISO 3308 (ISO-like) and Health Canada T-115 / ISO 20778 (CI-like)) for traditional cigarette smoking. 


\section{3.}

RESULTS AND DISCUSSION

\subsection{Commonality of analytical methodology}

Though analytical methodologies were not specified, all of the laboratories methods were similar. For example, all laboratories used an alcohol and an agitation method for extraction. GC-FID and GC-TCD with standard analytical separation columns were used for analysis. This common analytical approach was applied to the collaborative study used to support CRM No 84 (6).

\subsection{Collection of aerosol-choice of parameters}

\subsubsection{Puff shape}

Puff profile shape can be configured on conventional smoking machines based on a choice of several possible algorithms. For e-cigarette aerosol collection, bell shaped (Gaussian), square-shaped (constant volume), and triangle profiles have been previously explored by the CORESTA E-Vapor Sub-Group (9).

The devices in this study were puff (airflow) activated e-cigarettes which are activated at a pre-set airflow threshold that is not adjustable by the user. Due to the activation requirements, difference in ACM yield may be noted based on choice of profile shape and resulting puff velocity. This may be especially true with a short puff duration, such as the 2-s duration used for ISO 3308 puffing (8). Exemplary data, produced by one of the participating laboratories in separate tests conducted in their laboratory, is displayed in Table 3 . In this example, overall nicotine yield over 400 puffs using a square-shaped puff was $\sim 1 \mathrm{mg}$ higher than either a bell- or triangle-shaped puff. Due to the variable puff velocity in bell-shaped puffs, the square-shaped puff profile was favored during study development to allow for consistent device activation and provide a more consistent output over a range of product designs.

Figure 1, which shows the puff magnitude, exemplifies this difference. In Figure 1 a), a hypothetical product with a low flow rate for activation of the device is displayed with a square-shaped machine puff and a bell-shaped machine puff overlaid. In this case, there would be no difference in

Table 3. Impact of profile shape on yield. Varied puff profile shape with a short puff duration - aerosol nicotine yield $(\mathrm{mg}) \pm \mathrm{SD}$.

\begin{tabular}{l|ccc}
\hline \multirow{2}{*}{ Pad } & \multicolumn{3}{|c}{ Profile $^{\text {a }}$} \\
\cline { 2 - 4 } & Bell-shaped & Triangle-shaped & Square-shaped \\
\hline $1^{\text {st }} 50$ puffs & $0.48 \pm 0.12$ & $0.58 \pm 0.19$ & $0.69 \pm 0.14$ \\
$2^{\text {nd }} 50$ puffs & $0.38 \pm 0.11$ & $0.33 \pm 0.12$ & $0.54 \pm 0.14$ \\
$3^{\text {rd }} 50$ puffs & $0.24 \pm 0.10$ & $0.28 \pm 0.10$ & $0.34 \pm 0.11$ \\
$4^{\text {th }} 50$ puffs & $0.29 \pm 0.08$ & $0.24 \pm 0.09$ & $0.38 \pm 0.10$ \\
$5^{\text {th }} 50$ puffs & $0.25 \pm 0.07$ & $0.22 \pm 0.07$ & $0.38 \pm 0.07$ \\
$6^{\text {th }} 50$ puffs & $0.20 \pm 0.06$ & $0.19 \pm 0.07$ & $0.30 \pm 0.07$ \\
$7^{\text {th }} 50$ puffs & $0.19 \pm 0.06$ & $0.19 \pm 0.06$ & $0.28 \pm 0.06$ \\
$8^{\text {th }} 50$ puffs & $0.17 \pm 0.05$ & $0.15 \pm 0.05$ & $0.23 \pm 0.05$ \\
400 puffs total & $2.19 \pm 0.64$ & $2.17 \pm 0.74$ & $3.14 \pm 0.69$ \\
\hline
\end{tabular}

a Cl-like puffing parameters; displayed as the average \pm one standard deviation; $n=20$.

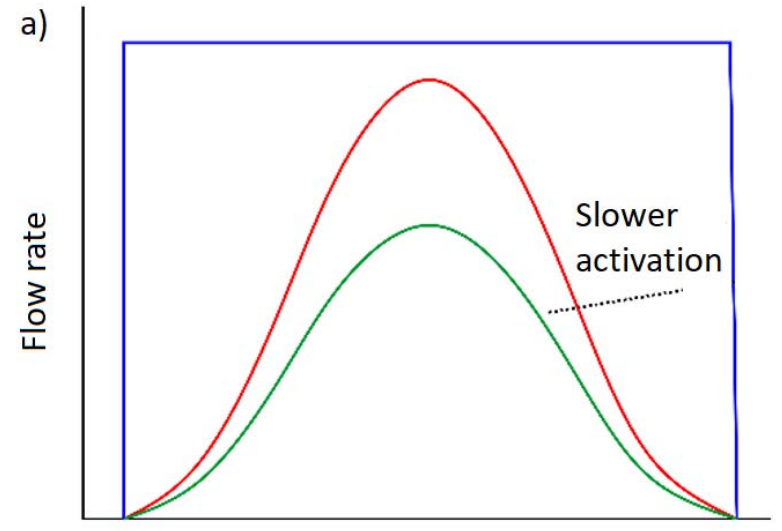

Time
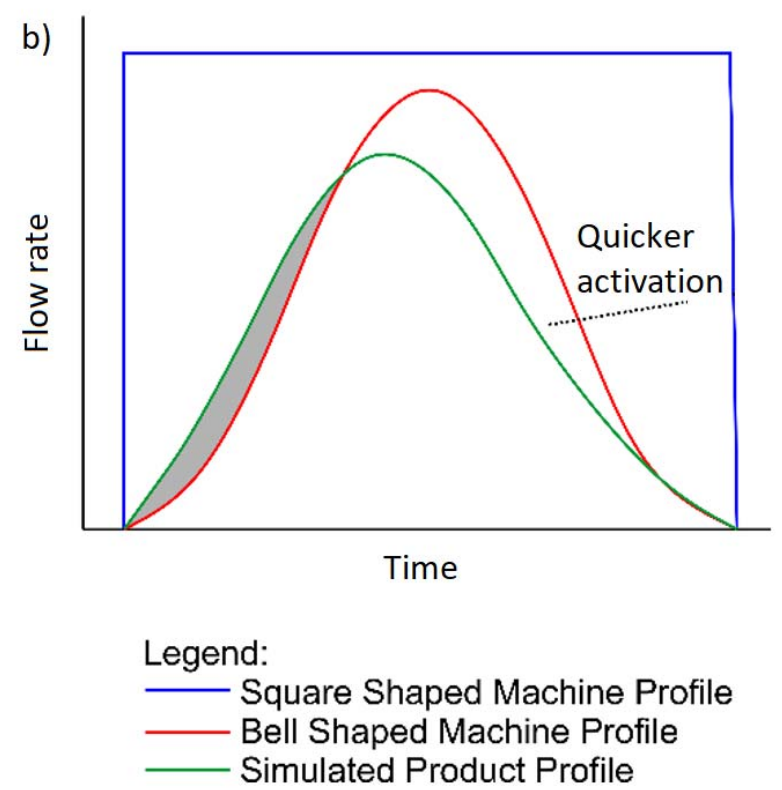

Figure 1. Puff profile diagrams (why square was favoured). Common puff profile algorithms for aerosol collection compared to possible device puff profile shape. In Figure a) the device has a relatively slow start-up. Square-shaped and bell-shaped machine profiles would give similar yield results. In Figure b) the device has a relatively quick start-up time, and the bell-shaped profile may give lower yields than the square-shaped profile.

yield based on puff profile shape because both profile shapes fully encompass the product's puff. On the other hand, for Figure $1 \mathrm{~b}$ ), a hypothetical product with a high flow rate for activation of the device is displayed. The bellshaped profile does not reach a volume sufficient for collection until after the product would be producing aerosol while the square-shaped profile does. In the case of this product, the square-shaped profile would give a higher yield than the bell-shaped profile since the device is activated longer during each puff. This may or may not be relevant for some product characterization studies but may be important for studies attempting to compare data generated in multiple laboratories, especially when comparing a range of products collected with different or unknown puff profiles. Puff profile shape was not varied for the potential candidate puffing regimes; a square-shaped profile shape was used in each test case. 
Table 4 a. Impact of puff frequency on yield.

\begin{tabular}{l|c|c|c|c|c|c|c|c}
\hline Puffing regime & Puff count & $\begin{array}{c}\text { Volume } \\
(\mathrm{mL} / \mathrm{min})\end{array}$ & $\begin{array}{c}\text { Nicotine } \\
(\mathrm{mg} / \mathrm{cig})\end{array}$ & $\begin{array}{c}\text { ACM } \\
(\mathrm{mg} / \mathrm{cig})\end{array}$ & $\begin{array}{c}\text { Water } \\
(\mathrm{mg} / \mathrm{cig})\end{array}$ & $\begin{array}{c}\text { Nicotine } \\
\text { (mg/puff) }\end{array}$ & $\begin{array}{c}\text { ACM } \\
\text { (mg/puff) }\end{array}$ & $\begin{array}{c}\text { Water } \\
\text { (mg/puff) }\end{array}$ \\
\hline $55 / 3$ / 30 & 60 & 110 & 1.2 & 73.2 & 12.5 & 0.020 & 1.22 & 0.21 \\
$55 / 3 / 60$ & 60 & 55 & 1.0 & 63.9 & 11.0 & 0.016 & 1.07 & 0.18 \\
\hline
\end{tabular}

Table $4 \mathbf{b}$. Impact of puff frequency on yield. Impact of puff collection period on yield collected during a day or across a week.

\begin{tabular}{l|c|c|c|c|c|c}
\hline Puff blocks & $35 \mathrm{~mL}, 1$ day & $55 \mathrm{~mL}, 1$ day & $65 \mathrm{~mL}, 1$ day & $35 \mathrm{~mL}, 1$ week & $55 \mathrm{~mL}, 1$ week & $65 \mathrm{~mL}, 1 \mathrm{week}$ \\
\hline $1^{\text {st }} 90$ puffs & 116.9 & 133.5 & 140.9 & 115.8 & 130.4 & 137.9 \\
$2^{\text {nd }} 90$ puffs & 101.2 & 109.6 & 115.6 & 100.1 & 107.9 & 116.3 \\
$3^{\text {rd }} 90$ puffs & 88.9 & 94.2 & 97.4 & 84.7 & 89.4 & 97.8 \\
$4^{\text {th }} 90$ puffs & 71.7 & 80.0 & 80.8 & 72.8 & 76.0 & 83.5 \\
Total & 378.6 & 417.2 & 434.7 & 373.3 & 403.7 & 435.5 \\
\hline
\end{tabular}

\subsubsection{Puff volume}

In this study, the choice of puff volume for the potential candidates' puffing regimes was based on having a puff velocity high enough to consistently activate the device, but not so high as to cause issues with product or puffing equipment performance. From preliminary work leading up to this study, there was a concern with some products having inconsistent activation under the ISO 3308 standard of $35-\mathrm{mL}$ puff volume over $2 \mathrm{~s}(8)$. The maximum puff volume for some commercial smoking machines, in standard configuration, is $70 \mathrm{~mL}$. Based on these factors, the puff volume was varied between $55 \mathrm{~mL}$ and $70 \mathrm{~mL}$ for the potential candidate puffing regimes in the study.

\subsubsection{Puff duration}

Device activation is an important consideration for puff duration. For standard cigarette smoking regimes, e.g., ISO 3308 (8), a puff duration of $2 \mathrm{~s}$ is employed. For e-cigarettes, $2 \mathrm{~s}$ was considered as too short a duration since the coil would not have sufficient time to reach the operating temperature required to produce a consistent amount of aerosol. A 5-s puff duration was considered but due to the puff volume limitations in this study, was eliminated because the low flow rate $(11 \mathrm{~mL} / \mathrm{s})$ could potentially lead to inconsistent activation of the device. Thus, 3-s and 4-s durations were compared in this study.

\subsubsection{Puff frequency}

Puff frequency was set at one puff every $30 \mathrm{~s}$ for vaping machine testing based on several practical reasons. In a separate investigation, puff frequencies of a puff every $30 \mathrm{~s}$ and $60 \mathrm{~s}$ were tested, and aerosol samples were collected sequentially across multiple days. Data from this investigation are shown in Table $4 \mathrm{a}$ and Table $4 \mathrm{~b}$. These results indicated that yields were not affected by the puff frequency and collection periods tested. For example, a frequency of one puff every $30 \mathrm{~s}$ was equivalent in yield to a frequency of one puff every $60 \mathrm{~s}$, and collection of 360 puffs in one day was equivalent in yield to the same number of puffs collected across one week. Thus, longer puff frequencies and collection periods increased collection time with no apparent technical benefit. Also, based on device performance data for some products, a puff frequency significantly shorter than one puff every $30 \mathrm{~s}$ may lead to device overheating or device failure. In the end, while a consumer may take more than one puff in $30 \mathrm{~s}$, the objective in this study was not to match vaping practices for some consumers; rather, the objective was to establish a practical puff frequency that could be used for standardized machine testing of electronic cigarette products. Thus, a frequency of one puff every $30 \mathrm{~s}$ was the most practical conclusion.

\subsubsection{Number of puffs per collection}

Puff block was set at 25 puffs per collection to a maximum of 300 puffs using one battery charge. The study was designed to collect sufficient information to compare the regimes. Three hundred puffs would reach the maximum for some but not all products and blocks of 25 puffs would allow several data points even for shorter lifetime products. This puff number specification was adequate for this particular study but may not be applicable in all studies. Thus, recommendations for puff number per puff block, number of puff blocks, and number of battery charges should not be taken based solely on this study.

\subsection{Evaluation of regimes}

\subsubsection{Selection criteria}

From this study, the factors that determined the recommended puffing regime included few or no issues with device or equipment failure attributable to the regime, collection of sufficient ACM for testing, little or no impact on ACM composition, and good overall precision.

\subsubsection{Machine or product performance issues}

At least until e-cigarette-specific aerosol collection machines become more commonly used, it is important to ensure that the recommended regime will be compatible with conventional smoking machines such as described by CERULEAN (4) and BORGWALDT (5). E-cigarette researchers with a background in cigarette smoking have employed 
Table 5. Comparison of overall ACM across regimes. Impact of regime choice on total ACM yield (mg).

\begin{tabular}{|c|c|c|c|c|c|c|}
\hline Sample & & Regime 1 & Regime 2 & Regime 3 & Regime 4 & Range $^{2}$ \\
\hline \multirow{3}{*}{ Lab 1-Rechargeable } & Avg & 647 & 677 & 621 & 629 & $9 \%$ \\
\hline & SD & 46 & 60 & 45 & 74 & \\
\hline & $\%$ RSD & $7 \%$ & $9 \%$ & $7 \%$ & $12 \%$ & \\
\hline \multirow{3}{*}{ Lab 2-Rechargeable } & Avg & 253 & 289 & 226 & 279 & $24 \%$ \\
\hline & SD & 60 & 14 & 25 & 13 & \\
\hline & $\%$ RSD & $24 \%$ & $5 \%$ & $11 \%$ & $5 \%$ & \\
\hline \multirow{3}{*}{ Lab 2-Disposable } & Avg & 537 & 590 & 542 & 611 & $13 \%$ \\
\hline & SD & 79 & 30 & 79 & 48 & \\
\hline & $\%$ RSD & $15 \%$ & $5 \%$ & $15 \%$ & $8 \%$ & \\
\hline \multirow{3}{*}{ Lab 3-Rechargeable } & Avg & 377 & 416 & 370 & 369 & $12 \%$ \\
\hline & SD & 35 & 52 & 50 & 44 & \\
\hline & $\%$ RSD & $9 \%$ & $13 \%$ & $14 \%$ & $12 \%$ & \\
\hline \multirow{3}{*}{ Lab 3-Disposable } & Avg & 234 & 267 & 268 & 270 & $14 \%$ \\
\hline & SD & 46 & 30 & 39 & 22 & \\
\hline & $\%$ RSD & $20 \%$ & $11 \%$ & $14 \%$ & $8 \%$ & \\
\hline \multirow{3}{*}{ Lab 4-Rechargeable } & Avg & 258 & 303 & 265 & 284 & $16 \%$ \\
\hline & SD & 9 & 17 & 17 & 11 & \\
\hline & $\%$ RSD & $4 \%$ & $6 \%$ & $6 \%$ & $4 \%$ & \\
\hline \multirow{3}{*}{ Lab 4-Disposable } & Avg & 891 & 924 & 870 & 942 & $8 \%$ \\
\hline & SD & 118 & 70 & 111 & 162 & \\
\hline & $\%$ RSD & $13 \%$ & $8 \%$ & $13 \%$ & $17 \%$ & \\
\hline
\end{tabular}

a Range $=\left[2 \times \frac{\text { Max }- \text { Min }}{M a x+M i n}\right] \times 100$

where, Max = maximum average value, Min = minimum average value

Table 6. E-cigarette weight loss vs. ACM yield. Ratio of e-cigarette weight loss to ACM collected - comparison across test regimes.

\begin{tabular}{|c|c|c|c|c|c|c|c|}
\hline & $\begin{array}{c}\text { Lab 1- } \\
\text { Rechargeable }\end{array}$ & $\begin{array}{c}\text { Lab 2- } \\
\text { Disposable }\end{array}$ & $\begin{array}{c}\text { Lab 2- } \\
\text { Rechargeable }\end{array}$ & $\begin{array}{c}\text { Lab 3- } \\
\text { Disposable }\end{array}$ & $\begin{array}{c}\text { Lab 3- } \\
\text { Rechargeable }\end{array}$ & $\begin{array}{c}\text { Lab 4- } \\
\text { Disposable }\end{array}$ & $\begin{array}{c}\text { Lab 4- } \\
\text { Rechargeable }\end{array}$ \\
\hline Test 1 & 1.0 & 1.0 & 1.0 & 1.1 & 1.0 & 1.0 & 0.9 \\
\hline Test 2 & 0.4 & 1.0 & 1.0 & 1.1 & 1.1 & 1.0 & 1.0 \\
\hline Test 3 & 1.0 & 1.0 & 1.0 & 1.1 & 1.1 & 1.0 & 0.9 \\
\hline Test 4 & 1.0 & 1.0 & 1.0 & 1.1 & 1.0 & 1.0 & 1.0 \\
\hline
\end{tabular}

conventional cigarette smoking machines for e-cigarette testing with little adaptation necessary. This was the case with all the laboratories in the study. In this study, each participant used conventional 20-port linear smoking machines equipped with standard puff engines capable of a maximum puff volume of $70 \mathrm{~mL}$. No technical issues were noted using the $55 \mathrm{~mL}$ puff volume or with varied puff duration. There were a few technical issues noted for tests with 70-mL puff volumes, possibly because this is the maximum volume for the puff engines used. One lab reported issues with machine failure with $70-\mathrm{mL}$ puff volumes. Two laboratories reported that smoking machine modifications, such as air pressure adjustment, were necessary for testing with 70-mL puff volumes. No product failures were attributed to any of the smoking regimes. Thus, based on machine performance, each of the regimes was considered adequate for standardization. However, due to the modifications that may be necessary for $70-\mathrm{mL}$ puffing, $55 \mathrm{~mL}$ was found to be the most suitable puff volume.

\subsubsection{Impact of regime on overall yields}

$\mathrm{ACM}$ is an indication of overall device performance. Results were compared for each product between the test regimes. Results were not compared between samples, as there was no expectation that any of the samples were in common between the laboratories. Overall yield, determined from combining the yields from all puff blocks collected, were similar for the four regimes (Regime 1 through 4) under consideration (Table 5); no practical or statistically significant differences were noted for any of the products. Precision for overall yields, as displayed in Table 5, was similar for each of the regimes, as well. Additionally, a comparison between e-cigarette weight loss and ACM indicated that results were similar between the regimes tested. Ideally, the weight loss of the e-cigarette and the weight gain of the particulate trap would be virtually the same, however, since PG and glycerin are hygroscopic, slight differences between device weight loss and ACM were not unexpected. As displayed in Table 6, 
Table 7. Comparison of ACM composition across regimes. Range in analyte percent composition across the regimes for each sample.

\begin{tabular}{l|c|c|r|r}
\hline Sample & $\begin{array}{c}\text { Total } \\
\text { PG }\end{array}$ & $\begin{array}{c}\text { Total } \\
\text { nicotine }\end{array}$ & $\begin{array}{c}\text { Total } \\
\text { glycerin }\end{array}$ & $\begin{array}{r}\text { Total } \\
\text { water }\end{array}$ \\
\hline $\begin{array}{l}\text { Range of \% Composition } \\
\text { a }\end{array}$ & & & \\
Lab 1-Rechargeable & $47-48$ & $1.2-1.2$ & $26-27$ & $11-13$ \\
Lab 2-Disposable & $56-58$ & $1.8-1.9$ & $28-29$ & $8-11$ \\
Lab 2-Rechargeable & $57-59$ & $1.8-1.9$ & $28-29$ & $8-12$ \\
Lab 3-Disposable & $\mathrm{NA}^{\mathrm{c}}$ & $1.6-1.6$ & $71-76$ & $20-20$ \\
Lab 3-Rechargeable & $\mathrm{NA}$ & $1.3-1.4$ & $72-76$ & $15-16$ \\
Lab 4-Disposable & $42-47$ & $1.0-1.2$ & $33-39$ & $15-18$ \\
Lab 4-Rechargeable & $34-41$ & $1.4-1.5$ & $41-44$ & $11-13$ \\
\% Difference in \% Composition & & & & \\
Lab 1-Rechargeable & $3 \%$ & $2 \%$ & $4 \%$ & $21 \%$ \\
Lab 2-Disposable & $4 \%$ & $4 \%$ & $5 \%$ & $33 \%$ \\
Lab 2-Rechargeable & $3 \%$ & $3 \%$ & $4 \%$ & $32 \%$ \\
Lab 3-Disposable & $\mathrm{NA}$ & $1 \%$ & $6 \%$ & $3 \%$ \\
Lab 3-Rechargeable & $\mathrm{NA}$ & $2 \%$ & $7 \%$ & $9 \%$ \\
Lab 4-Disposable & $10 \%$ & $22 \%$ & $16 \%$ & $21 \%$ \\
Lab 4-Rechargeable & $19 \%$ & $8 \%$ & $6 \%$ & $17 \%$ \\
\hline
\end{tabular}

a Calculated as: Analyte $(\mathrm{mg}) / \mathrm{ACM}(\mathrm{mg}) \times 100$

b Calculated as:

$(2 \times($ Max \%Composition-Min \%Composition $)) /($ Max + Min $) \times 100$

c Not applicable

the ratio of weight loss to ACM values was near 1 in most cases. Thus, each of the test regimes was fit for purpose based on overall (ACM) yields.

\subsubsection{Impact on relative yields of analytes}

Another consideration for recommending a standard regime is whether the regime would impact composition of the aerosol. Thus, the percent of each analyte in the ACM was calculated as analyte $(\mathrm{mg}) / \mathrm{ACM}(\mathrm{mg}) \times 100$. As shown in Table 7 as the range and the percent difference in percent composition for each regime and sample, in most cases the percent composition varied by no more than $10 \%$ among the regimes for a given analyte except for water, which is expected to have high variability due to its ubiquitous nature and the hygroscopic properties of the product. For example, for sample Lab 1-Rechargeable, the percent composition of nicotine was $1.22 \%, 1.24 \%, 1.21 \%$, and $1.24 \%$ for Tests $1,2,3$, and 4, respectively. This is a range of $0.03 \%$ (as an absolute value) or $2 \%$ (calculated as percent difference). Thus, there appears to be no impact on the composition of the ACM based on regime choice for the regimes tested. This result is reasonable based on the function of the products as a direct transfer of the e-liquid to the aerosol. Thus, as with overall yield results, there is no advantage or disadvantage among the regimes tested.

\subsubsection{Impact of regime on cumulative yield or puff trending}

The ACM was collected discretely rather than in total; 25 puffs were collected per pad up to 300 puffs. With this collection scheme, delivery profile trends may be assessed. While the overall yields were similar among the regimes, the delivery profiles show that there was an impact on puff
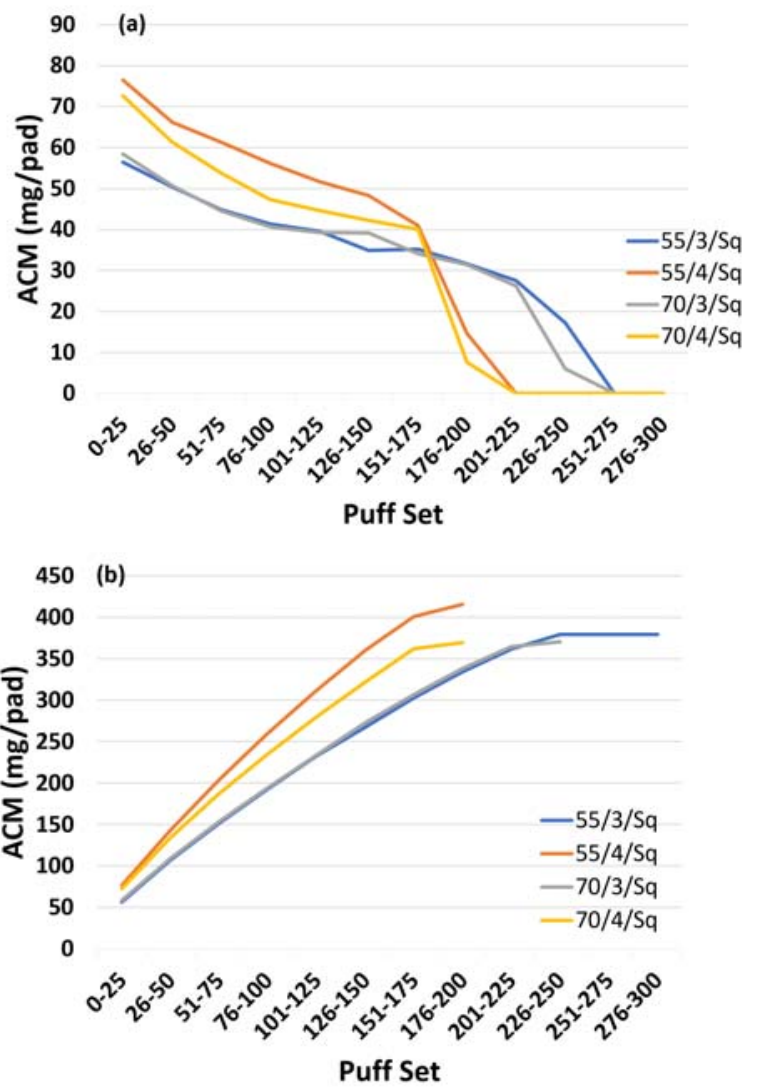

Figure 2. Puff profile diagram. Puff block results example shown as (a) puff block to puff block yield trending and (b) cumulative yield.

blocks from choice of puff duration ( $3 \mathrm{~s}$ versus $4 \mathrm{~s}$ ). On the other hand, puff volume did not appear to impact the delivery profile. This trending is exemplified in Figure 2 for one of the samples. Trend lines for the regimes using 3-s duration, 55/3/30/square and 70/3/30/square, are virtually identical. The trend lines for the 4-s duration regimes, $55 / 4 / 30$ /square and 70/4/30/square, also group together. Note also that the 4-s trends have higher yields and fewer puff blocks than the 3 -s trends.

The puff count, not the overall yield, is impacted by puff duration. It was clear from the study results that longer puff durations increased the per-puff yield which led to a corresponding decrease in the total puff count.

\subsubsection{Difference in yield variability}

The relative standard deviation (\%RSD) was calculated for each puff block to determine if any of the regimes appeared to have improved precision. End-of-life puffs would be expected to be highly variable regardless of the regime. Therefore, partial last puff blocks were not considered in the evaluation of variability. Collection variability results, calculated as the percent relative standard deviation (\%RSD) of the ACM delivery for each puff block, are shown in Table 8 and Table 9. Puff block precision was relatively high and generally similar among and between the blocks. For all products tested, $80 \%$ of the RSD values were less than $15 \%$ regardless of regime. Thus, it is considered, among all tested regimes, none of the regimes had a particular advantage with regards to yield variability. 
Table 8. Range in analyte percent composition across the regimes for each rechargeable sample.

\begin{tabular}{|c|c|c|c|c|c|c|c|c|c|c|}
\hline \multirow{2}{*}{ Sample } & \multirow{2}{*}{ Profile } & \multicolumn{9}{|c|}{ Puff numbers } \\
\hline & & $0-25$ & $26-50$ & $51-75$ & $76-100$ & $101-125$ & $126-150$ & $151-175$ & 176-200 & $201-225$ \\
\hline \multirow{4}{*}{ Lab 1-Rechargeable } & $55 / 3 / 30 / \mathrm{Sq}$ & 7 & 8 & 9 & 9 & 7 & 10 & 9 & 9 & \\
\hline & $55 / 4 / 30 / S q$ & 7 & 10 & 11 & 11 & 11 & 11 & & & \\
\hline & $70 / 3 / 30 / \mathrm{Sq}$ & 10 & 8 & 8 & 10 & 8 & 9 & 8 & 7 & \\
\hline & $70 / 4 / 30 / \mathrm{Sq}$ & 14 & 14 & 14 & 14 & 14 & 11 & & & \\
\hline \multirow{4}{*}{ Lab 2-Rechargeable } & $55 / 3 / 30 / \mathrm{Sq}$ & 17 & 17 & 20 & 18 & 18 & 18 & 16 & 13 & \\
\hline & $55 / 4 / 30 / S q$ & 11 & 7 & 6 & 5 & 7 & 9 & & & \\
\hline & $70 / 3 / 30 / \mathrm{Sq}$ & 18 & 18 & 18 & 18 & 19 & 19 & 20 & 24 & 6 \\
\hline & $70 / 4 / 30 / \mathrm{Sq}$ & 14 & 11 & 9 & 9 & 9 & 6 & & & \\
\hline \multirow{4}{*}{ Lab 3-Rechargeable } & $55 / 3 / 30 / \mathrm{Sq}$ & 11 & 16 & 17 & 26 & & & & & \\
\hline & $55 / 4 / 30 / \mathrm{Sq}$ & 10 & 8 & 7 & \multirow{3}{*}{17} & & & & & \\
\hline & $70 / 3 / 30 / S q$ & 11 & 12 & 13 & & & \multirow{2}{*}{\multicolumn{3}{|c|}{$\begin{array}{c}80 \% \text { of all } \% \text { RSD } \\
\text { values }<15 \% \\
\end{array}$}} & \\
\hline & $70 / 4 / 30 / \mathrm{Sq}$ & 11 & 7 & 8 & & & & & & \\
\hline \multirow{4}{*}{ Lab 4-Rechargeable } & $55 / 3 / 30 / \mathrm{Sq}$ & 6 & 5 & 7 & 6 & & & & & \\
\hline & $55 / 4 / 30 / S q$ & 7 & 6 & 5 & 4 & & & & & \\
\hline & $70 / 3 / 30 / \mathrm{Sq}$ & 7 & 6 & 7 & 5 & & & & & \\
\hline & $70 / 4 / 30 / S q$ & 7 & 7 & 5 & & & & & & \\
\hline
\end{tabular}

Table 9. Range in analyte percent composition across the regimes for each disposable sample.

\begin{tabular}{|c|c|c|c|c|c|c|c|c|c|c|c|c|}
\hline \multirow{2}{*}{ Sample } & \multirow{2}{*}{ Profile } & \multicolumn{11}{|c|}{ Puff numbers } \\
\hline & & $0-25$ & $26-50$ & $51-75$ & $76-100$ & $101-125$ & $126-150$ & $151-175$ & $176-200$ & 201-225 & 226-250 & 251-275 \\
\hline \multirow{4}{*}{ Lab 2-Disposable } & $55 / 3 / 30 / \mathrm{Sq}$ & 19 & 22 & 24 & 29 & 34 & & \multirow{2}{*}{\multicolumn{4}{|c|}{$\begin{array}{c}80 \% \text { of all } \% \text { RSD } \\
\text { values }<15 \%\end{array}$}} & \\
\hline & $55 / 4 / 30 / \mathrm{Sq}$ & 6 & 6 & 5 & 7 & & & & & & & \\
\hline & $70 / 3 / 30 / S q$ & 6 & 9 & 9 & 15 & & & & & & & \\
\hline & $70 / 4 / 30 / \mathrm{Sq}$ & 6 & 6 & 7 & 7 & & & & & & & \\
\hline \multirow{4}{*}{ Lab 3-Disposable } & $55 / 3 / 30 / \mathrm{Sq}$ & 6 & 8 & 9 & 9 & 11 & 13 & 9 & 9 & 19 & & \\
\hline & $55 / 4 / 30 / \mathrm{Sq}$ & 12 & 13 & 11 & 12 & 12 & 13 & 15 & & & & \\
\hline & $70 / 3 / 30 / S q$ & 8 & 11 & 14 & 17 & 18 & 20 & 15 & 18 & 18 & & \\
\hline & $70 / 4 / 30 / \mathrm{Sq}$ & 7 & 11 & 12 & 13 & 17 & 18 & 19 & & & & \\
\hline \multirow{4}{*}{ Lab 4-Disposable } & $55 / 3 / 30 / \mathrm{Sq}$ & 10 & 8 & 6 & 8 & 6 & 8 & 5 & 5 & 9 & & \\
\hline & $55 / 4 / 30 / \mathrm{Sq}$ & 6 & 6 & 8 & 5 & 8 & 7 & 4 & 5 & & & \\
\hline & $70 / 3 / 30 / \mathrm{Sq}$ & 3 & 5 & 4 & 4 & 4 & 4 & 6 & 5 & 22 & 8 & 20 \\
\hline & $70 / 4 / 30 / \mathrm{Sq}$ & 13 & 13 & 12 & 11 & 7 & 12 & 14 & & & & \\
\hline
\end{tabular}

\subsubsection{Flow-rate considerations}

While there were no issues with device failure based on choice of regime for any of the products in the study, certain combinations of volume and duration may have lead to failure based on too low a flow-rate to activate puffactivated devices. The exact flow needed to trigger a unit is product dependent and was apparently sufficient in all cases for the products in the study. For the regimes tested, the flow rate ranged from $13.8 \mathrm{~mL} / \mathrm{s}$ to $23.3 \mathrm{~mL} / \mathrm{s}$. Considering a possibility that at flow rates lower than $15 \mathrm{~mL} / \mathrm{s}$, there may be inconsistent activation for some products, Regime 2, $55 \mathrm{~mL} / 4 \mathrm{~s}$ (i.e., $13.8 \mathrm{~mL} / \mathrm{s}$ ), was not favored.

\subsubsection{ISO-like and CI-like vaping}

Testing using ISO 35/2/60 (ISO-Like) and Canadian Intense 55/2/30 (CI-Like) (puffing parameters were included in the study for informational purposes but were not included in the evaluation for recommending a regime. For researchers with a background in cigarette testing or for study designs which include comparison with cigarette smoke, ISO (8) and/or CI (10) parameters may be of particular relevance. There is a possibility of inconsistent device actuation when using bell-shaped puff profiles (as discussed earlier and shown in Figure 1). In this study, there were no issues with product performance with either of these regimes. Simply based on the results of this study, either of these regimes would be viable choices if appropriate for a particular study design and product type. The 
primary difference between these regimes and the test regimes in the study was that the 25-puff-block yields were lower for these regimes. Thus, use of either of these regimes for life-time puffing experiments and experiments for which a certain weight of ACM is collected would require more puffs (longer collection times) than would be required for testing with the other regimes evaluated in this study.

\subsection{Recommendation of one regime}

There was an expectation at the start of the study that there would be a clear preference among the regimes tested but this was not the case. Most regimes met all of the selection criteria and in fact all four would be fit for purpose based on the set of products tested. All regimes tested, including ISO and CI, yielded sufficient ACM for analytical testing; however, as discussed above, ISO and CI based regimes were not under consideration. Precision for overall and puff block yields were adequate for all four candidate regimes. Mass transfer and relative composition results were similar among the test candidate regimes. Based on criteria around machine performance, the two regimes which used 70-mL puff volume, Regimes 3 and 4, were not recommended. Thus, the choices were narrowed to Regime 1 and Regime 2 . Strictly based on results of the testing here, either of these regimes could be recommended. On the other hand, there was a possibility of device failure for certain products when the combination of volume and duration resulted in too low a flow rate (e.g., less than $15 \mathrm{~mL} / \mathrm{s}$ flow rate obtained using Regime 2 of $55 \mathrm{~mL}$ and $4 \mathrm{~s}$ duration). Therefore, Regime 2 was not recommended. Thus, Regime 1, a 55-mL square-shaped puff of $3 \mathrm{~s}$, with a frequency of one puff every $30 \mathrm{~s}$ is recommended as a standard collection regime for e-cigarette aerosol collection. Note that the number of total puffs, puffs per puff block, and trapping media are dependent upon study objectives.

In addition to these standards, some commonality in reporting is recommended. Reporting units that may be useful for fostering a collective understanding of the research include $\mathrm{mg} / \mathrm{pad}$ for incremental collection and $\mathrm{mg} /$ total puffs for total collection on a single pad for particulate matter collection. In addition to analytes of interest, collection and reporting of ACM, puff counts, and e-cigarette weight change are useful quality-enhancing measures and would aid collaborative understanding of results. Reporting of information regarding battery charging and number of cycles and the use of analytical blanks would be useful, as well.

\subsection{Limitations and additional work}

Limitations to the work that should be considered include that only products of a conventional design that were available at the time of study execution, were included in the study. Choice of regime parameters may need to be redefined as additional product types are tested. Puff volume and combinations of volume and duration were limited by capabilities of conventional smoking machines in standard configurations. This limitation allows for the quickest upstart of a recommended regime. In the meantime, e-cigarette collection equipment with higher flexi- bility is being developed and standardized. As this equipment becomes commonly available, parameters may be revisited.

Additional research related to e-cigarette aerosol characterization should include development of standardized analytical methodology for e-cigarette aerosol testing. A proficiency study using the recommended regime from this study was conducted in 2017 and reported separately (3). Development of CORESTA Recommended Methods for routine analytical testing for e-cigarette aerosol generation and collection (7) and testing of major components in e-cigarette aerosol was also completed (6).

\section{CONCLUSIONS}

The purpose of this study was to evaluate selected puffing regimes for analytical evaluation of e-cigarette devices. The test regimes were designed around previous experience with a range of commercial products and the capabilities of currently available standard test equipment. Parameters evaluated were puff duration ( $3 \mathrm{~s}$ and $4 \mathrm{~s}$ ) and puff volume $(55 \mathrm{~mL}$ and $70 \mathrm{~mL}$ ). Parameters which were held constant for the study were puff block increment and maximum total puffs ( $\leq 300$ puffs collected in blocks of 25), puff frequency (one puff every $30 \mathrm{~s}$ ), and puff profile shape (square). The study was performed using e-cigarettes available at the time of study execution (2014-2015), namely disposable and rechargeable e-cigarettes. The conclusions reached in the study need to be confirmed with other types of e-cigarettes which became popular since this study was conducted, such as variable-power e-cigarette devices (mods) or pods-type e-cigarettes. Study participants used their choice of test products, which were not disclosed, and their choice of test equipment and analytical methods, which are summarized in this report. Results for major constituents (ACM, water, nicotine, glycerin, and PG) were collected and used for the evaluation.

Criteria for recommendation of a test regime included few or no issues with device or equipment failure attributable to the regime; collection of sufficient ACM for testing; impact on ACM composition; and good overall precision. Yields were similar for the four test regimes. Delivery profile trends were dependent on puff duration, but not on puff volume. Precision was acceptable and similar for all regimes. It may be best to avoid the use of a 70-mL puff volume due to limitation of commercially available standard smoking machines. Therefore, the two regimes tested with $70-\mathrm{mL}$ puffs are not recommended at this time. There were two regimes tested with $55-\mathrm{mL}$ puff volume ( $3 \mathrm{~s}$ and $4 \mathrm{~s}$ ). While at the start of the study, there was concern that the flowrate for $55 \mathrm{~mL}$ with a $4 \mathrm{~s}$ duration may not be sufficient for puff activation, there were no issues with this regime in this study. The limited number of products tested in the study is not sufficient to have full confidence in this regime for all devices, so the combination of $55-\mathrm{mL}$ puff volume with $4 \mathrm{~s}$ puff duration is not recommended at this time. Thus, a regime using a square-shaped $55-\mathrm{mL}$ puff of $3 \mathrm{~s}$ duration taken twice a minute is recommended as an acceptable standard regime for aerosol collection from electronic cigarettes. 


\section{ACKNOWLEDGMENTS}

We greatly appreciate the contributions from the participating laboratories; the product suppliers; Dr. Narendra Meruva; and White Cloud and Red Kiwi, who supplied some of the e-cigarettes for testing.

\section{CONFLICTS OF INTEREST}

At the time of this study, authors Tayyarah, Stevens, and Garner were employed by companies that market e-cigarettes. Products used in the study were supplied to the group by the product manufacturers. No funds were supplied to the laboratories that provided study results.

\section{REFERENCES}

1. Beauval, N., M. Verriele, A. Garat, I. Fronval, R. Dusautoir, S. Antherieu, G. Garcon, J. Lo-Guidice, D. Allorge, and N. Locoge: Influence of Puffing Conditions on the Carbonyl Composition of E-Cigarette Aerosols; Int. J. Hyg. Environ. Health 222 (2019) 136146. DOI: 10.1016/j.ijheh.2018.08.015

2. Farsalinos, K.E., V. Voudris, and K. Poulas: E-Cigarettes Generate High Levels of Aldehydes Only in "Dry Puff" Conditions; Addiction 110 (2015) 1352-1356. DOI: 10.1111 /add.12942

3. Cooperation Center for Scientific Research Relative to Tobacco (CORESTA): Technical Report: 2014 Preliminary Aerosol Proficiency Study; 2017. Alderman, S., Stevens, R. \& R., Tayyarah. Available at: https://www.coresta.org/sites/default/files/technical documents/main/EVAP-089-CTR_2014Preliminary AerosolProf.Study_Oct2017.pdf(accessed May 2019)

4. Cerulean: Smoking Machines. http://www.cerulean. com/en/solutions/product/rotary-smoking-machines (accessed May 2018)

5. Borgwaldt: Smoking Machines. https://www.borg waldt.com/en/products/smoking-machines.html (accessed May 2019)

6. Cooperation Center for Scientific Research Relative to Tobacco (CORESTA): Recommended Method No 84 .
Determination of Glycerin, Propylene Glycol, Water and Nicotine in the Aerosol of E-Cigarettes by Gas Chromatographic Analysis; (2017) Available at: https://www.coresta.org/sites/default/files/technical_d ocuments/main/CRM_84-June2017.pdf (accessed December 2019)

7. Cooperation Center for Scientific Research Relative to Tobacco (CORESTA): Recommended Method No 81 . Routine Analytical Machine for E-Cigarette Aerosol Generation and Collection - Definitions and Standard Conditions; (2015). Available at: https://www.coresta. org/sites/default/files/technical_documents/main/ CRM_81.pdf (accessed May 2019)

8. International Organization for Standardization (ISO): ISO 3308:2012 Routine Analytical Cigarette-Smoking Machine - Definitions and Standard Conditions; ISO, Geneva, Switzerland, 2012. Available at: https:/www.iso.org/obp/ui/\#iso:std:iso:3308:ed-5:v1:en (accessed July 25, 2019)

9. Cooperation Center for Scientific Research Relative to Tobacco (CORESTA): Technical Report: 2014 Electronic Cigarette Aerosol Parameters Study; 2015. Garner C., Stevens R.D. and R., Tayyarah. Available at: https://www.coresta.org/sites/default/files/technical_d ocuments/main/ECIG-CTR_ECigAerosolParameters2014Study_March2015.pdf (accessed May 2019)

10. Health Canada, Canadian Ministry of Justice: Tobacco Reporting Regulations. SOR/200-273. Registration 2000-06-26. Part 3: Emissions from Designated To bacco Products; (2000) available at: https:/laws-lois. justice.gc.ca/eng/regulations/sor-2000-273/Full Text.html (accessed Oct 2020)

Corresponding author:

Amit Gupta, MS

Battelle Memorial Institute

505 King Avenue

Columbus, $\mathrm{OH}, \mathrm{USA}$

Tel.: +1 6146425227

Fax: +16144276227

E-mail: guptaamit@battelle.org 